\title{
FORMAÇÃO CONTINUADA:
}

\section{ENTENDIMENTOS E VIVÊNCIAS DOS PROFESSORES DE EDUCAÇÃO FÍSICA NO CONTEXTO DO GOVERNO ESTADUAL (RS) GESTÃO 2007/2010}

\author{
ESP. MARISA RIGHI \\ Especialista em Educação Física Escolar pelo Centro de Educação Física e \\ Desportos da Universidade Federal de Santa Maria (CEFD/UFSM), Professora \\ de Educação Física da Rede Estadual do Rio Grande do Sul (Seduc/RS) \\ (Silveira Martins - Rio Grande do Sul - Brasil) \\ E-mail: marisarighi@terra.com.br
}

\section{DRA. ELIZARA CAROLINA MARIN}

Doutora em Ciências da Comunicação pelo Centro de Ciências da Comunicação da Universidade do Vale dos Sinos (CCC/UNISINOS), Professora adjunta do Centro de Educação Física e Desportos da Universidade Federal de Santa Maria (CEFD/UFSM)

(Santa Maria - Rio Grande do Sul - Brasil)

E-mail: elizaracarol@yahoo.com.br

\section{DRA. MARISTELA DA SILVA SOUZA}

Doutora em Ciências do Movimento Humano pelo Centro de Educação Física e Desportos da Universidade Federal de Santa Maria (CEFD/UFSM), Professora adjunta do Centro de Educação Física e Desportos da Universidade Federal de Santa Maria (CEFD/UFSM)

(Santa Maria - Rio Grande do Sul - Brasil)

E-mail:souzamaris@bol.com.br

\section{RESUMO}

Esta pesquisa focaliza a formação continuada, levando-se em consideração os entendimentos e as vivências dos professores de Educação Física no contexto do Governo Estadual do RS, gestão 2007-2010, e as diretrizes nacionais e estaduais que a regem. O estudo foi realizado por meio de pesquisa bibliográfica, documental e de entrevistas com professores de Educação Física da Rede Pública de Ensino no âmbito urbano e rural. Os resultados demonstram que as medidas adotadas pelo governo não atendem às necessidades e expectativas dos professores e não garantiram o direito à formação continuada intituídas nas diretrizes nacionais e estaduais.

PALAVRAS-CHAVE: Educação fsica; formação continuada; políticas públicas; vivências. 
A Lei n. 9.394/96, do Ministério da Educação, trouxe possibilidades para os profissionais de educação, propondo-lhes a formação em serviço, também denominada formação continuada. As escolas passaram a ter a responsabilidade de propor estudos, jornadas, cursos aos seus professores, como forma de atualização docente.

Atualmente tem-se reconhecido que a formação inicial é apenas o primeiro passo no caminho da formação profissional e que, em virtude da provisoriedade do conhecimento, há necessidade de uma formação permanente ou continuada e de o profissional docente adotar a postura de professor-estudante, professor-pesquisador.

Nesse sentido, alguns questionamentos decorrem neste histórico período do Estado do Rio Grande do Sul sobre a relação professor de Educação Física e formação continuada. "Propostos pelas escolas e secretarias estaduais, os processos de formação atendem aos objetivos e necessidades da prática pedagógica do professor de Educação Física?"; "Qual o entendimento dos professores de Educação Física sobre a contribuição da formação continuada para sua área?"; "É possível contemplar as especificidades da Educação Física em um processo de formação generalista?"; "O que a Secretaria de Educação do Estado do Rio Grande do Sul gestão 2007/20 I 0 propôs em termos de formação continuada para os professores e qual o entendimento dos professores de Educação Física sobre essa formação?".

Com base em tais questionamentos, o estudo busca saber como se processa a formação continuada de professores de Educação Física que atuam em escolas estaduais de municípios do Rio Grande Sul e, mais especificamente, identificar a compreensão quanto às propostas de formação continuada do governo estadual no período pesquisado.

Para consecução da pesquisa foram realizados dois levantamentos: um bibliográfico e um documental, mais as entrevistas aos professores participantes. A pesquisa bibliográfica serviu de alicerce para compreender o tema central do estudo, ou seja, a formação continuada. A pesquisa documental possibilitou que se construísse um mapa, ainda que breve, das legislações afins: a nacional e a do estado do Rio Grande do Sul, das normativas do governo estadual (gestão 2007/20 l0) para a formação continuada dos professores, assim como das Diretrizes Nacionais para a Educação Física. Já as entrevistas colaboraram para compreender como a formação continuada se dá no contexto da prática docente, especificamente para os professores de Educação Física. As entrevistas foram realizadas com oito professores, sendo cinco da região da Quarta Colônia' e três de Santa Maria, que

1. Trata-se de uma região próxima ao município de Santa Maria, formada por nove (9) municípios, e que agrega características rurais. 
atuam nas escolas estaduais dos seguintes municípios: Faxinal do Soturno, Silveira Martins, Restinga Seca e Santa Maria. Os critérios para a seleção de tais municípios se deram em virtude da possibilidade de abarcar escolas e professores do contexto rural e urbano e da proximidade com a Universidade Federal de Santa Maria. Para a realização das entrevistas com os professores foram marcados dias e horários específicos. É importante destacar que os nomes dos professores que aparecem no estudo são fictícios para que suas identidades fiquem resguardadas.

\section{FORMAÇÃO CONTINUADA: A LEGISLAÇÃO E SEUS ASPECTOS CONTRADITÓRIOS}

A formação profissional do professor inicia na formação inicial e segue no percurso da atuação profissional, consubstanciando, assim, o que se denomina formação continuada. A primeira é realizada nos cursos de formação acadêmica; a segunda, em serviço.

Diferentes pesquisadores, com diferentes abordagens (destaca-se MOLINA NETO, 1997; DAMIANI; MELO, 2006; BRACHT et al, 2002) têm denunciado o fato de a maioria das propostas de formação continuada estarem organizadas com fins imediatistas, políticos ou financeiros, portanto, desvinculados dos fazeres dos professores e dos contextos escolares em que se inserem. Tais programas e propostas teórico-metodológicas contribuem, por um lado, para o acirramento da fragmentação do saber, para o silenciamento dos professores; por outro, para estimular o comércio sob a égide da formação continuada.

Portanto, para melhoria da qualidade da formaç̧ão profissional e a valorização do trabalho pedagógico, faz-se imprescindível uma articulação entre instituições formadoras (no caso, as instituições de ensino superior), e a Escola Básica, de modo a valorizar as experiências e conhecimentos desenvolvidos pelos professores na trajetória profissional, bem como, conhecimento sobre a legislação que rege o direito à formação continuada em âmbito federal e estadual.

Entre os anos de 1996 e 2010 um conjunto de projetos governamentais focando a formação continuada de professores foi proposto no Brasil. Em decorrência disso, foram gerados avanços, como também contradições. A Lei de Diretrizes e Bases da Educação Nacional (BRASIL, 1996) tem representado, no plano nacional, um ponto de apoio para que as instituições públicas e privadas promovam e desenvolvam ações no campo da educação e da formação de professores. Conforme explicita o Art. 67, os sistemas de ensino promoverão a valorização dos profissionais da educação, assegurando-lhes, inclusive nos termos dos estatutos e dos planos de carreira do magistério público: 
I - ingresso exclusivamente por concurso público de provas e títulos;

II - aperfeiçoamento profissional continuado, inclusive com licenciamento periódico remunerado para esse fim (grifo nosso);

III - piso salarial profissional;

IV - progressão funcional baseada na titulação ou habilitação e na avaliação do desempenho;

$\checkmark$ - período reservado a estudos, planejamento e avaliação, incluído na carga de trabalho (grifo nosso);

$\mathrm{VI}$ - condições adequadas de trabalho.

Vale situar também o que o Plano Nacional de Educação (BRASIL, 200 I , p. 82) propõe como objetivos a serem alcançados para a valorização do magistério:

- uma formação profissional que assegure o desenvolvimento da pessoa do educador enquanto cidadão e profissional, o domínio dos conhecimentos objeto de trabalho com os alunos e dos métodos pedagógicos que promovam a aprendizagem;

- um sistema de educação continuada que permita ao professor um crescimento constante de seu domínio sobre a cultura letrada, dentro de uma visão crítica e da perspectiva de um novo humanismo (grifo nosso);

- jornada de trabalho organizada de acordo com a jornada dos alunos, concentrada num único estabelecimento de ensino e que inclua o tempo necessário para as atividades complementares ao trabalho em sala de aula;

- salário condigno, competitivo, no mercado de trabalho, com outras ocupações que requeiram nível equivalente de formação;

No Rio Grande do Sul, as bases legais que orientam e/ou impulsionam a formação continuada dos professores da Rede Estadual de ensino encontram-se no Plano Estadual de Educação e no Estatuto e Plano de Carreira do Magistério Público do Rio Grande do Sul. O Plano Estadual de Educação traz como objetivos e metas (RIO GRANDE DO SUL, 2005, P. 99- I00:

- Garantir espaço de estudo na jornada semanal do professor, através das horas-atividade, com o objetivo de contribuir para a qualidade do ensino;

- Desenvolver ação articulada com os municípios e as instituições de educação superior, com vistas a oportunizar formação superior em cursos de licenciatura para os docentes em atuação nas escolas públicas de educação básica;

- Priorizar a formação continuada do magistério de forma articulada com a avaliação externa do rendimento escolar do aluno e a melhoria da qualidade do ensino, promovendo ações conjuntas com as universidades e outras instituições de educação superior;

- Desenvolver para os professores e servidores programas de ensino a distância que possam ser atualizados através de cursos semipresenciais modulares;

- Garantir a formação inicial e continuada de forma a superar a dicotomia existente entre a teoria e a prática, apontando para a importância dos novos saberes (grifos nossos). 
O Estatuto e Plano de Carreira do Magistério Público do Rio Grande do Sul (Secretaria da Educação do RS, 1974), em seu Art. 3. ${ }^{\circ}$, determina que a Carreira do Magistério Público Estadual tem como princípios básicos:

I - Profissionalização, entendida como dedicação ao Magistério, para o que se tornam necessárias:

a) qualidades pessoais, formação adequada e atualização constante, objetivando o êxito da educação e acessos sucessivos na Carreira (grifo nosso);

IV - Valorização da qualificação decorrente de cursos e estágios de formação, atualização, aperfeiçoamento ou especialização. (grifo nosso).

Também os Art. 62 e 91, que tratam respectivamente dos direitos, das licenças para a qualificação e da qualificação propriamente dita, determinam que:

Art. 62 - São direitos do pessoal do Magistério Público Estadual:

$\mathrm{VI}$ - ter assegurada a oportunidade de freqüentar cursos de formação, atualização e especialização profissional;

Art. 9 I - A licença para a qualificação profissional consiste no afastamento do professor ou do especialista de educação de suas funções, sem prejuízo de seus vencimentos, assegurada sua efetividade para todos os efeitos da Carreira, e será concedida:

I - para freqüência a cursos de formação, aperfeiçoamento ou especialização formal;

II - para participação em congressos, simpósios ou outras promoções similares, no País ou no estrangeiro, desde que referentes à educação e ao Magistério (grifos nossos).

Como se pode observar, estão evidenciadas tanto na legislação nacional quanto na estadual, as responsabilidades do sistema de ensino, assim como as parcerias por eles reconhecidas como promissoras para a institucionalização de políticas mais efetivas e duradouras, no que tange ao desenvolvimento profissional dos professores e a consequente melhoria da qualidade do ensino. Contudo, como veremos no decorrer deste artigo, na gestão 2007/20 I 0, o governo estadual do RS, na esteira das práticas do desenvolvimentismo neoliberal, desviou seu foco para outros objetivos que não os da educação, com profundos resultados prejudiciais ao processo da educação continuada, sobretudo na educação física.

Em relação à proposta dos níveis de promoção da carreira, a secretária de educação² do Estado sugeriu implementação de "avaliações periódicas da formação continuada dos professores", em que a promoção deve considerar a constante atualização dos educadores. "Dessa forma, os professores passariam por exames de

2. Referência à secretária estadual de educação que atuou no período de 02 de janeiro de 2007 a setembro de 2009 e que sofreu severa crítica por sua atuação, principalmente pelo Centro dos Professores do Estado do Rio Grande do Sul - Sindicato dos Trabalhadores em Educação (CEPERS), em função das tentativas de implementar políticas que ferem conquistas históricas do magistério público estadual. 
verificação dos conhecimentos em períodos predeterminados, visando à progressão na estrutura funcional". (RIO GRANDE DO SUL, 2009, p. I).

Consoante a esta medida, a implantação de um sistema de remuneração variável por desempenho também esteve entre as propostas apresentadas. Segundo a secretária de educação, isso significaria a conquista do 14 . $^{\circ}$ salário. No entanto, tudo dependeria dos resultados da aprendizagem dos alunos para que houvesse alterações no vencimento. (RIO GRANDE DO SUL, 2009). O Sistema de Avaliação do Rendimento Escolar do Rio Grande do Sul (SAERS) e os exames promovidos pelo Ministério da Educação serviriam como instrumentos para a identificação do desempenho dos alunos.

Como o expõe Baccin (2010) no estudo sobre as políticas educacionais do governo do RS (gestão 2007-20 I0), tais medidas, ainda que seguindo a linha meritocrática, além de, por um lado, culpabilizarem o professor pela má qualidade da educação, por outro, ainda permitem que o governo se desresponsabilize das suas obrigações com as políticas públicas.

O governo (gestão 2007-20 I 0) também criou o Decreto n. ${ }^{\circ} 44.86$ I , de 04 de janeiro de 2007 (RIO GRANDE DO SUL, 2007a), no qual algumas de suas propostas vieram vetar a participação de professores em seminários e congressos realizados fora do Estado e impedir a troca de experiências entre profissionais de mesma área de conhecimento. Tal decreto se contrapõe à legislação de apoio à formação continuada, especificamente ao Art. 9I-II, que trata do afastamento dos professores "para participação em congressos, simpósios ou outras promoções similares, no País ou no estrangeiro, desde que referentes à educação e ao Magistério". (RIO GRANDE DO SUL, 1974).

O Ofício Circular, de 19 de outubro de 2007, estabelecido pela Secretaria de Educação do Estado do RS, é outro exemplo de contraposição às normativas nacionais e estaduais, pois determina que: "não serão válidos para fins de Promoção, Encontros e Cursos realizados por professores e especialistas dentro do seu horário de trabalho e que o mesmo evento (encontro/curso) não pode ser duplamente certificado, devendo haver a opção [ou] por um ou [por] outro" (RIO GRANDE DO SUL, 2007b). Esta determinação demonstra o descompromisso do Estado com o processo de formação continuada, uma vez que desvincula o espaço de formação do espaço de trabalho do professor e joga a este a responsabilidade de achar, junto ao seu ao seu tempo livre, as horas para o estudo e a qualificação.

Sem a intenção de aprofundar questões ideológicas na discussão de tais exigências, é possível afirmar que as modalidades de formação continuada dos professores encontram-se limitadas naquilo que condiz a desenvolvimento e qualidade. Atualmente, grande número de professores vem abandonando o magistério 
devido aos baixos salários e às condições de trabalho nas escolas. Bem-formar em número e qualidade profissionais do magistério é apenas uma parte da tarefa. É preciso também criar condições para que o professor se mantenha no trabalho; e, para que haja perspectivas de crescimento e qualificação permanente nas escolas, é necessário ainda respeitar seu plano de carreira e os direitos da classe.

As leis expostas aqui demonstram forte contradição no que se refere ao papel do poder público no processo de formação. Ao mesmo tempo em que uma legislação o aponta como direito e salienta sua importância, outra similar trata de negá-lo, no sentido de estreitar as anteriormente previstas possibilidades de desenvolvimento. Ainda que façam parte de um projeto de formação coletiva no âmbito de um estabelecimento escolar ou de uma rede ampliada, esses dispositivos atuais se restringem a algumas seções de formação, concentradas em três ou quatro dias, ou de seis a oito jornadas parciais durante o ano escolar; desse modo, não atendem às necessidades nem dos professores nem do alunado.

A busca de novos conhecimentos e a construção de redes de informações com outros colegas como parte da prática educativa contribuem efetivamente para transformar a escola. A apropriação do conhecimento construído historicamente, servindo de base ao recentemente produzido, mantém o professor informado dos acontecimentos nacionais e internacionais, bem como "do avanço da ciência e da técnica" (SOARES et al, 1992, p. 31), leva-o a apreender a provisoriedade do conhecimento e a entender que a história é construída em resposta às necessidades quotidianas, entre estas, as necessidades educacionais. Taffarel (1999) chama a atenção para a necessidade de os professores se reconhecerem como intelectuais comprometidos com as reivindicações da classe trabalhadora. Para a autora, é pelo trabalho e por sua capacidade de relações e mediações que se constroem alternativas para além do processo capitalista. Tal visão recoloca, para cada professor, a relevância da intervenção. Não se pode ser indiferente, e é esta possibilidade histórica formada com a força da luta dos trabalhadores que urge reconhecer como necessidade histórica. Desse modo, criam-se condições objetivas para que a possibilidade se converta de fato em realidade.

\section{FORMAÇÃO CONTINUADA: A EXPERIÊNCIA VIVENCIADA POR PROFESSORES DE EF}

Para verificar de que modo se dá a formação continuada no contexto político do governo do Estado do RS (gestão 2007-20 I0), os pesquisadores buscaram dialogar com professores da região estudada para identificar o que segue: [1] o conhecimento sobre seus direitos e sobre os encaminhamentos do Governo do 
Estado do Rio Grande do Sul para os trabalhadores da educação; [2] as atividades de formação continuada, realizadas nos últimos anos, e os órgãos promotores desses encontros; [3] o que esperam da formação continuada e como esta contribui para suas práticas pedagógicas, particularmente no que se refere às especificidades da Educação Física.

Os professores participantes, em sua maioria, destacaram que a participação em formação continuada ocorreu na própria escola, voltada para temas gerais do campo da educação, não contemplando a especificidade da Educação Física. Enfocam aspectos de como o professor pode trabalhar com o educando em sala de aula, ou seja, as formas de ensinar, de educar e de conviver com os alunos. Por exemplo, o congresso ${ }^{3}$ promovido pela Faculdade Palotina de Santa Maria (FAPAS), Santa Maria (RS), em 2009, com o tema "Educação humanizadora e os desafios da diversidade: educar para o respeito às diversidades é educar para a vida", em que foram discutidos temas sobre educação e transformação social, educação e afetividade na relação com as diferenças, entre outros. $\bigcirc$ relato apresentado a seguir deixa visível o enfoque dos eventos de formação continuada de que participaram os autores de tais depoimentos:

Participo na própria escola e fiz a minha especialização em 2007. Participo na escola porque é o que tem sido oferecido por aí e acaba resumindo sempre no mesmo ponto, em cursos gerais. Eu procuro curso específico da educação física, mas também acabo na medida do possível participando de todos que falam de educação. Nos últimos anos participei do Mercomovimento, ${ }^{4}$ mas não teve nada de novo. O que fez modificar talvez um pouco a prática e repensar foi a especialização. (Joana)

Infere-se que independentemente de o espaço de formação ser específico da área da Educação Física ou ser um espaço que trate de questões educacionais gerais, esta deverá proporcionar a compreensão da totalidade comum a qualquer tipo de formação, ou seja, que os conhecimentos compreendam as relações do ser humano com a sociedade. Dessa forma, conforme Soares et al (1992), todo o educador terá condições de orientar a sua especificidade de conhecimento através de concepções claras sobre sociedade, ser humano e educação. No caso da Educação Física, a compreensão e o trato com o conhecimento devem se dar numa perspectiva sócio-histórica dos elementos que constituem a cultura corporal.

3. III Congresso Internacional de Educação, ocorrido na Faculdade Palotina de Santa Maria (FAPAS), de 22 a 25 de abril de 2009, com duração de 43 horas.

4. O Mercomovimento trata-se de um congresso realizado na cidade de Santa Maria (RS), de caráter não científico, em que o conhecimento é dividido em modalidades esportivas e oferecido em forma de cursos. Encontra-se na sua XI edição e é realizado pelo Centro de Educação Física e Desportos através da Associação Desportiva da Universidade Federal de Santa Maria (ADUFSM). 
Os professores destacam que os espaços de formação se constituem em momentos esporádicos e impostos verticalmente, sem planejamento e sem relação com as necessidades do coletivo de professores.

Olha, a minha escola, oferece cursos de 40 horas, ela organiza, ela promove e executa. Nessa parte de cursos eu vejo que se tornou um ritual, uma prática mesmo, todos os anos a escola tem que ter um curso, com dias determinados para a formação continuada dentro do calendário e todos tem que fazer, ou então leva falta. A escola tem dias pra cumprir com a formação continuada. A gente fica sabendo por meio do mural da escola e chama muito pouca atenção pois são assuntos repetidos e não resolvidos. (Laura)

Essa lógica de organização limita a relação entre os conhecimentos gerais da prática pedagógica e a especificidade da área da EF, fragmentando o conhecimento e dificultando a visão de totalidade.

No depoimento que segue fica evidente que os espaços de formação não são realizados por parte dos professores para responder aos problemas e necessidades de seus interesses, mas sim, a partir do que surge dentro das possibilidades de tempo e oferta.

Nos últimos anos a gente procurou fazer as atividades de formação continuada que estavam estabelecidas no calendário escolar da escola; não mais que isso. Nos governos que antecederam a este a gente teve o direito de fazer, de se ausentar da escola e deixar outro colega no nosso lugar para fazer cursos, e isso contava pra nossa promoção, pra nossa carreira. Então a gente participava muito mais de cursos de formação. Atualmente o governo 'trancou pé' e a gente só ta conseguindo fazer cursos que estejam previstos dentro do calendário. Então a gente acaba fazendo um por ano, no máximo dois, três cursos, e nos fins de semana para que não pegue nosso horário de trabalho, ou como te falei, só previsto no calendário. Os dois cursos de pós-graduação que eu fiz também foram feitos nos finais de semana; não pegavam horário de trabalho. Então é nesse sentido. Atualmente eu sinto falta de mais cursos, pois nesses últimos anos ficou um pouco de lado, ficou a desejar. A última atividade de que a escola participou foi no Patronato, o MOBREC. ${ }^{5}$ As instituições promovem e a $8^{a} C R E^{6}$ se diz parceira; mas naquele sentido, como já falei, se a gente parar, se os alunos ficarem em casa, não contar dia letivo, toda a escola participa. Não pode ser dentro do calendário; tem que estar fora do calendário do ano letivo. (Lúcia)

Os relatos realçam que as propostas de políticas educacionais impostas pelo governo do Estado do RS caminham para limitações cada vez maiores referentes aos direitos dos professores em participar de processos de formação continuada relacionados aos seus interesses e à apropriação de novos conhecimentos. Como

5. Movimento Brasileiro de Educadores Cristãos (MOBREC).

6. Coordenadoria Regional de Educação (CRE). 
está evidente na fala dos professores, e como é lei já instituída, há necessidade de liberação das coordenadorias, possibilitando, assim, a validação dos certificados para fins de pontuação de carreira.

Cabe destacar a experiência vivenciada pelos professores que atuam na Quarta Colônia no processo de formação continuada, promovido pelos professores do Centro de Educação Física e Desportos da UFSM nos anos de 2007 a 2009. Tal processo de Formação Continuada foi previsto com o comprometimento dos professores e em parceria com as direções das escolas, sendo que no primeiro ano de vigência também havia a parceria da $8^{\mathrm{a}}$ CRE, localizada em Santa Maria. A formação ocorria durante o período de trabalho, pois os encontros estavam previstos no calendário escolar e, assim, não invibializavam as aulas e tampouco prejudicavam aos alunos.

As diretrizes para a educação advindas do governo do Estado, as quais passaram a desconsiderar toda e qualquer forma de qualificação profissional no horário de trabalho, inviabilizaram não somente a parceria com a 8a CRE, como também o próprio processo de formação, uma vez que os certificados passaram a não mais ter validade para fins de progressão. Estabelecer o processo de formação fora do horário de trabalho gerou falta de condições objetivas para a participação dos professores, a exemplo do transporte para o deslocamento dos participantes via secretarias municipais. Uma nova organização, a partir deste decreto, exigiu dos professores "abrir mão" de seu tempo informal, o que causou evasão e a asfixia da proposta.

Os professores entrevistados que participaram da formação continuada, desenvolvida para o coletivo de professores que atuam na Quarta Colônia e promovida pela UFSM, destacam que o processo possibilitou o convívio entre os pares, com troca de experiências quanto à disciplina de Educação Física, agregando novos conhecimentos entre diferentes realidades vivenciadas nessa área educacional, possível de constatar no relato a seguir:

A troca de experiências é fundamental para a vida do profissional; e quando nos deparamos com situações-problemas, junto a colegas que já vivenciaram tais momentos, fica mais fácil resolvermos ou então acharmos soluções rápidas. E também a formação continuada faz com que a teoria e a prática se encontrem em alguns momentos e a partir daí busquemos juntos encontrar alternativas para soluções que estão a nossa frente e a gente não enxerga (Mauro).

Quando indagados sobre as motivações para a busca de processos de formação continuada, a maioria dos professores destacou que a troca de experiências com colegas da área, a qualificação e atualização para a prática docente e a obtenção de novas experiências para a prática pedagógica são os quesitos mais importantes. 
Também tem destaque, tanto para os professores entrevistados que atuam em Santa Maria, quanto para os que atuam na Quarta Colônia, a formação continuada vivenciada via Curso de Especialização em Educação Física Escolar, realizado e promovido pelo Centro de Educação Física e Desportos (UFSM), embora fique evidente os limites no seu desenvolvimento, a exemplo de não envolver as instituições escolares no seu processo de construção.

Os professores afirmam que esses cursos de pós-graduação relacionaram teoria e prática e também apresentaram novas maneiras de ensinar. A seguir, a declaração de Mauro elucida tanto a importância que o processo está gerando para a prática pedagógica do professor quanto o esforço que ele precisa realizar para participar, uma vez que os encontros ocorrem em horário coincidente das aulas, causando para ele uma sobrecarga de trabalho:

Buscamos sempre nos aperfeiçoar. No momento que nós crescemos como profissionais e aprendemos, a gente consegue transpor para o educando tudo que a gente aprendeu, pelo menos os métodos, consegue pelo menos, criticamente, situar-se frente a diversas situações que ocorram na escola. Alguns dizem: "Pô, tu vais fazer um curso de educação fisica escolar?", mas é ali que a gente ta aprendendo, porque a gente ta debatendo com os colegas novas ideologias, novos temas, entendendo por que era feito assim e não é mais. Então é esse o momento que a gente vai crescer como pessoa, como profissional e com certeza nosso aluno vai aprender também. (Mauro)

Com exceção da formação continuada proposta pelo CEFD/NFSM, em que as escolas não se envolveram na organização, mas disponibilizaram local e horário para os encontros, nas propostas de formação continuada em geral, são as escolas que organizam, promovem e executam, procurando envolver professores e funcionários.

$\mathrm{Na}$ opinião dos professores, a formação continuada deve contribuir para qualificar a ação pedagógica, para realizar uma autoavaliação do trabalho realizado, para buscar alternativas para os problemas e para inovar, mediante diferentes leituras de novos caminhos, conforme apontam os relatos a seguir:

A contribuição da formação continuada na nossa prática pedagógica é fazer com que nós cresçamos. O encontro com outros professores, tanto das escolas públicas como da própria Universidade, faz com que nós encontremos alternativas para as situações que se apresentam para o nosso dia a dia. (Mauro)

A formação continuada deve servir a de estímulo, de suporte, de referencial teórico para buscar resoluções de conflitos, pra dar uma qualidade melhor no trabalho, no dia-a-dia da escola. (Joana) 
Um aperfeiçoamento para que possa ajudar, no dia-a-dia, na sala de aula, no fazer pedagógico, que na grande maioria das vezes fica a distância, o abismo entre teoria e prática. O que os cursos oferecem não preenchem as necessidades e muito pouco acrescentam nas aulas. (Pedro)

Nesse sentido, deixam claro que o modo como a formação continuada tem sido proposta na escola atualmente não contribui para a prática do dia a dia. Os professores se ressentem com a falta de cursos e seminários específicos para cada disciplina e em que possam discutir sua prática pedagógica. Em relação aos conhecimentos sobre os direitos assegurados pelas leis, os professores entrevistados não têm muita clareza sobre as próprias conquistas da classe. $\bigcirc$ conhecimento sobre a legislação é agregado com o passar do tempo e de acordo com as necessidades surgidas nas discussões ocasionais; e, normalmente, restringe-se à questão salarial. Dessa forma, ignoram a extensão de seus direitos no âmbito da formação pedagógica e da formação continuada.

As manifestações do Centro dos Professores do Estado do Rio Grande do Sul - Sindicato dos Trabalhadores em Educação (CPERS), por meio de líderes e organizadores das assembleias, informam sobre os direitos adquiridos e a serem mantidos, e criticam que, muitas vezes, a principal reivindicação dos professores se restringe à questão salarial.

Sobre o tomar conhecimento em relação aos novos encaminhamentos do governo do Estado do Rio Grande do Sul, a maioria dos professores diz ter notícias através de e-mail, da mídia, do CPERS, das coordenadorias. Argumentam que as propostas do governo favorecem os que estão no poder; nunca o funcionalismo público. Os professores denunciam que o objetivo do governo é retirar os direitos adquiridos pelos professores, conquistados através de lutas ao longo dos anos, conforme evidencia o relato abaixo:

Acredito que o objetivo do governo é desmantelar o plano de carreira do magistério, tirando direitos históricos conquistados com muita luta pela categoria. O plano atual possibilita o avanço na carreira através de promoções por antiguidade e merecimento, avaliado através da participação em cursos, seminários; enfim, cursos de formação, atualização e especialização. Segundo os encaminhamentos do governo a licença-prêmio será transformada em licença para formação continuada, mas me pergunto: "Todos terão direito à licença-prêmio para se aperfeiçoarem?"; "E o professor poderá escolher a formação que pretende realizar?". (Pedro)

Percebe-se, então, que a qualidade da educação é voltada fundamentalmente ao mercado de trabalho, em uma perspectiva neoliberal ${ }^{7}$ que não leva em

7. Não é intenção neste artigo aprofundar a compreensão sobre neoliberalismo e seus desdobramentos para a educação pública. Para tal recomendamos Baccin (2010). 
consideração as necessidades do contexto escolar. Segundo Richit (2009, p. 14), para que os processos de formação promovam a incorporação do conhecimento pedagógico-tecnológico ao conhecimento específico de cada área é necessário que esses sejam favorecidos pela criação de políticas públicas específicas, bem como pelos programas das instituições formadoras e pelos gestores da educação. Além disso, a concretização das mudanças no sistema público de ensino que viabilizem a qualificação da educação, em particular na prática docente, depende também da conscientização dos diversos segmentos da escola (pais, alunos, professores, equipe diretiva). Com isso, cada um vai assumir seu papel nessa tarefa, quer seja buscando formação, incentivando a superação de desafios, apoiando as decisões da escola ou disponibilizando recursos para que novas estratégias pedagógicas sejam experimentadas.

Como enseja Baccin (20।0), o que se pode perceber é que o governo do Estado do RS, na gestão 2007/20 I 0, elaborou políticas educacionais que têm relações de colaboração com as diretrizes do Banco Mundial para esse setor, dentre as quais se destacam as ações em que o governo se coloca a favor da municipalização do ensino. Desse modo, ao modificar o plano de carreira do magistério, implementando um plano com metas a serem atingidas, no modelo meritocrático, e, ainda, pondo-se contra a implementação do piso salarial nacional, nos moldes de sua aprovação no Congresso Nacional, deixou de cumprir uma de suas funções que é ensejar a oferta da educação pública e suas correspondentes responsabilidades, como previsto em Lei.

Para atingir esses objetivos, portanto, o governo elaborou seus projetos e implementou um sistema de avaliação capaz de demonstrar se tais objetivos estão ou não se efetivando na prática. Além disso, são tais políticas que vão apontar a direção e os objetivos da educação e, ainda, influenciar para que ela se efetive, na prática, na organização do trabalho pedagógico das escolas.

\section{CONSIDERAÇÕES FINAIS}

A pesquisa demonstrou semelhanças nas respostas no que tange às concepções e experiências vivenciadas pelos professores que atuam em Santa Maria e na Quarta Colônia, em relação aos processos de formação continuada dos quais eles tenham participado. Segundo os dados das entrevistas, a formação continuada, do modo como vem sendo aplicada, na maioria dos casos não atende às expectativas alimentadas pelos professores, referentes à disciplina Educação Física. Em grande medida, as propostas são impostas e, além de não levarem em conta prioridades dos professores, precarizam sua participação através da falta de apoio e estrutura. 
Esse processo dificulta a relação entre os aspectos gerais do sistema educacional com as especificidades da área, uma vez que fragmenta o conhecimento e restringe o tempo de formação.

Além de o governo estadual na gestão 2007-20 I 0 não ter incentivado a formação continuada dos professores, dificultou a realização dos encontros, pois definiu arbitrariamente tanto o que tematizar quanto os mediadores dos debates e quando se realizariam os eventos. Tal gestão descumpriu as leis maiores que regem as políticas públicas da educação; por assim agir, pode-se afirmar, configurou-se num governo que atuou por decretos.

A pesquisa veio evidenciar que entre as leis federais e as leis estaduais há um descompasso, agravado, portanto, quando ambas ficam à mercê da política adotada pelo governo que assume cada gestão. Em outras palavras, a pesquisa explicita a inexistência de uma Política de Estado e, mais, a inexistência de uma política pública no Estado do Rio Grande do Sul que reconheça a importância da formação continuada de modo a atender aos interesses e necessidades dos professores em geral e dos de EF em particular.

Evidencia ainda, por meio da experiência concreta dos professores investigados, que atualmente os docentes da rede pública estadual não têm garantido o direito à formação continuada pelos órgãos públicos competentes. Diante dessa realidade, o que de mais grave este estudo pôde confirmar é que, ao mesmo tempo em que os professores são cobrados por governo, pais e sociedade em geral para que se qualifiquem, mediante esse poder público também serão responsabilizados pela má qualidade da educação.

A pesquisa aponta que a ausência de coesão e de organicidade entre leis federais, estaduais e municipais - que garantiriam avanços qualitativos em regime permanente no sistema educacional do país, transforma-se em fator de permissão para que governos descumpram a lei e extrapolem suas funções basilares.

\section{Continuing education: understandings and experiences of teachers of Physical Education in the context of State Government (RS) management 2007/2010}

ABSTRACT: This research focuses on lifelong learning, taking into account the understandings and experiences of physical education teachers in the context of the Provincial Government of Rio Grande do Sul, in the 2007-20 10 management and national and state guidelines that govern it. The study was conducted through literature, documents and interviews with teachers of Physical Education, Public Education in urban and rural areas. The results show that government policies do not meet the needs and expectations of teachers and are not guaranteed the right to continue the graduate education according to national guidelines and state. KEYWORDS: Physical Education; continuing education; public policies; experience. 


\section{Educación permanente: comprensión y experiencias de profesores de Educación Física en el contexto de Gobierno del Estado (RS) gestión 2007/2010}

RESUMEN: Esta investigación se centra en la educación permanente, teniendo en cuenta los entendimientos y experiencias de los profesores de educación física en el contexto del Gobierno Provincial de Río Grande del Sur, en la gestión 2007-20 1 0, y directrices nacionales y estatales que lo rigen. El estudio se realizó por medio de la literatura, documentos y entrevistas con los profesores de Educación Física, de la Educación Pública en los contextos urbanos y rurales. Los resultados muestran que las políticas gubernamentales no cumplen con las necesidades y expectativas de los profesores y no se garantiza el derecho a continuar la educación del titulado según las directrices nacionales y estatales.

PALABRAS-CLAVE: Educación Física; formación permanente; políticas públicas; experiencias.

\section{REFERÊNCIAS}

BACCIN, E.V.C. Educação física escolar: implicações das políticas educacionais na organização do trabalho pedagógico. 20 10. 135f. Dissertação (Mestrado em Educação). Programa de Pós-Graduação em Educação Física, Universidade Federal de Pelotas, Pelotas, 2010.

BRACHT, V. et al. A pratica pedagógica em Educação Física: A mudança a partir da pesquisaação. Revista Brasileira das Ciências do Esporte, Campinas v.23, n. 2, p. 9-29, jan. 2002.

BRASIL. Ministério da Educção e Cultura. Lei 10.172/01, de 09 de janeiro de 2001 . Aprova o Plano Nacional de Educação e dá outras providências. 200 I. Disponível em: < http//www. mec.gov.br/acs/pdf/pne.pdf>. Acesso em: 20 jun. 2010.

BRASIL. Ministério da Educação. Conselho Nacional de Educação. Lei de Diretrizes e Bases da Educação Nacional: lei n. 9394/96. Brasília, 1996. Resolução CNE/CES n. 7, de 31 de mar. 2004. Diretrizes Curriculares Nacionais para os cursos de Educação Física, em nível superior graduação plena. p. I-6.

DAMINANI, I. R.; MELO, C. K. Rede de/em formação: reflexões e apontamentos sobre a formação continuada. In: CONGRESSO SUL BRASILEIRO DE CIÊNCIAS DO ESPORTE, 3., 2006, Santa Maria. Anais... Santa Maria, 2006. v. I. p. 0 I - 12.

MOLINA NETO, V. A formação profissional em Educação Física e Esportes. Revista Brasileira de Ciências do Esporte, Campinas, v. 19, n. I, p. 34-4I, set. 1997.

NORONHA, M. I. A. Revisão da resolução CNE/CEB número 3/97, que fixa diretrizes para os novos Planos de Carreira e de Remuneração para o Magistério dos Estados, do Distrito Federal e dos Municípios, UF/DF, homologado pelo Senhor Ministro da Educação em 28/05/2009.

PRADO, R. O desafio da escola total. Revista Nova Escola, ano I7, n. I 56, p. 23-26, out. 2002. 
RICHIT, A. Formação continuada docente no Rio Grande do Sul: horizontes e contradições presentes nas políticas públicas. Disponível em: < http://www.2.cc.unesp.br/eventos/matemática>. Acesso em: 0 I out. 2009.

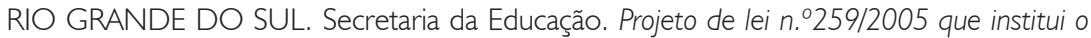
Plano Estadual de Educação e dá outras providências. 2005. Disponível em: < http://www. educacao.rs.gov.br>. Acesso em: 09 out. 2009.

RIO GRANDE DO SUL. Secretaria da Educação. Lei n. ${ }^{\circ}$ 6.672, de 22 de abril de 1974. Estatuto e Plano de Carreira do Magistério Público do Rio Grande do Sul. Disponível em: <http://www.educacao.rs.gov.br/>. Acesso em: 22 dez. 2010.

RIO GRANDE DO SUL. Secretaria da Educação. Decreto n. ${ }^{\circ} 44.861$, de 04 de janeiro de 2007. 2007a. Disponível em: <http://wnw.educacao.rs.gov.br>. Acesso em: 09 out. 2009.

RIO GRANDE DO SUL. Secretaria da Educação. Ofício circular n.919, 2007b. Disponível em: <http://www.educacao.rs.gov.br>. Acesso em: 09 out. 2009.

RIO GRANDE DO SUL (Estado). Novo Plano de Carreira do Magistério é discutido com escolas da região de Bagé. 13 maio 2009. Disponível em: <www.jusbrasil.com.br/politica/2669228/ novo-plano-de-carreira-do-magisterio-e-discutido-com-escolas-da-regiao-de-bage $>$. Acesso em: 22 out. 2009.

SOARES, C. L. et al. Metodologia do ensino da Educação Física. São Paulo: Cortez, 1992.

VEIGA, I. P. A. Projeto político-pedagógico da escola: uma construção coletiva. In: VEIGA, I. P. A. (Org.). Projeto político-pedagógico da escola: uma construção possível. Campinas: Papirus, 1995. p.19-22.

TAFFAREL, C. N. Z. Políticas públicas e educação física \& esportes no Brasil: reformas ou ruptura? Entrevista concedida ao Professor Nivaldo A. Nogueira David em 31 mar. 1999. Pensar a Prática, v.2, 1999. Disponível em: <http://wmw.revistas.ufg.br/>. Acesso em: 10 out. 2009.

Recebido: I 4 fev. 201 I

Aprovado: 2 fev. 2012

Endereço para correspondência:

Elizara Carolina Marin

CEFD/UFSM

Cidade Universitária, n. ${ }^{\circ} 1000$

Bairro Camobi

Santa Maria-RS

CEP 97I05-900 